\title{
Strategies for Predicting Centrifugal Pump Performance Characteristics by Validating Blade Shape Configurations. Introducing the Trojan Horse Method
}

\author{
J. C. Statharas ${ }^{a^{*}}$, E. S. Valamontes ${ }^{\mathrm{b}}$, P. Filiousis ${ }^{\mathrm{a}}$, N. W. Vlachakis ${ }^{\mathrm{a}}$ \\ ${ }^{a}$ National and Kapodistrian University of Athens, Sciences General Department, Psachna, Evias, 34400, Greece. \\ ${ }^{b}$ E.S. Valamontes, Professor, Department of Electrical \& Electronics Engineering, University of West Attica, Greece. \\ ${ }^{a}$ Professor, Corresponding Author $\quad{ }^{a}$ Ingenieur, External Research Fellow $\quad{ }^{a}$ Professor, Research Fellow
}

\begin{abstract}
A simple and easy to apply numerical method called Trojan Horse method-for pump head and efficiency estimation is presented. This is a contribution on centrifugal pump characteristics prediction using empirical relations based on performance maps of known pumps developed by some researchers. The present method evaluates a specific flow rates parameter, as well as some empirical equations for impeller geometrical data. The introduced modelling equations based on the blade shape configurations provide the pump characteristic lines. The method is validated by applying it to various commercial centrifugal pumps with known performance maps produced by their developers. From the cases examined, it can be stated that the present model can be applied to predict performances of centrifugal pumps of any diameter, particularly at all efficiency regions that the pump is supposed to operate according to its geometrical data. As a result the proposed method provides a satisfactory approximation of industrial centrifugal pumps' performance curves, constituting a potential tool for pump researchers and manufacturers.
\end{abstract}

Keywords-Centrifugal pump, performance map, empirical method, impeller, characteristic line, numerical prediction.

\section{INTRODUCTION}

\subsection{Centrifugal pump description}

Centrifugal pumps are the most common type of pumps used to move fluids through a piping system. They are devices that find extensive applications particularly in mining, chemical and mechanical industry. The fluid enters the pump impeller along or near to the rotating axis and is accelerated by the impeller, flowing radially outward or axially into a diffuser or volute chamber, from where it exits into the downstream piping system. The main parts of a centrifugal (or radial) pump are shown in Fig.1.1.

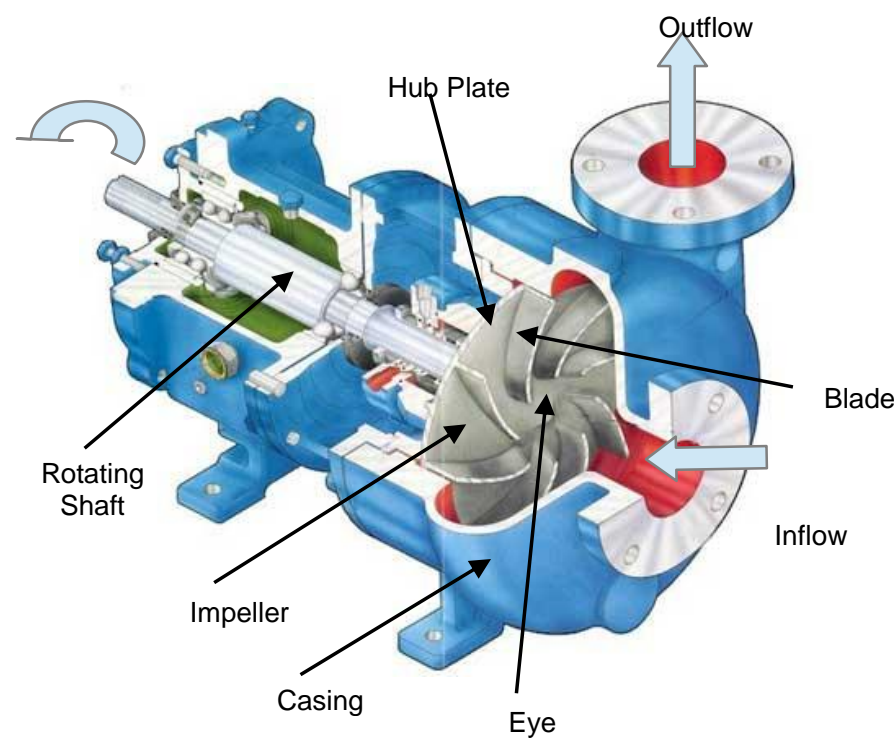

Fig.1.1. Main components of a centrifugal pump (Taken from [47])

\subsection{Impeller's geometry}

The basic component of a centrifugal pump is a rotor (or impeller) in which a number of blades is attached (see Fig.1.2). Fig.1.3 shows the impeller geometry explaining its main geometrical characteristics. 


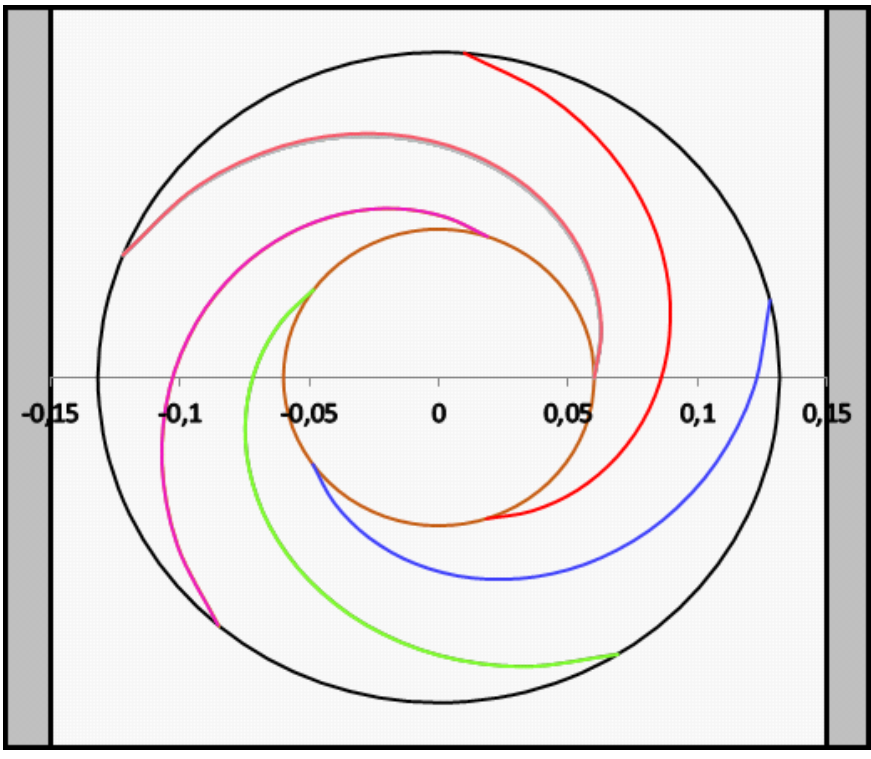

Fig. 1.2: Schematic view for a five-bladed impeller model
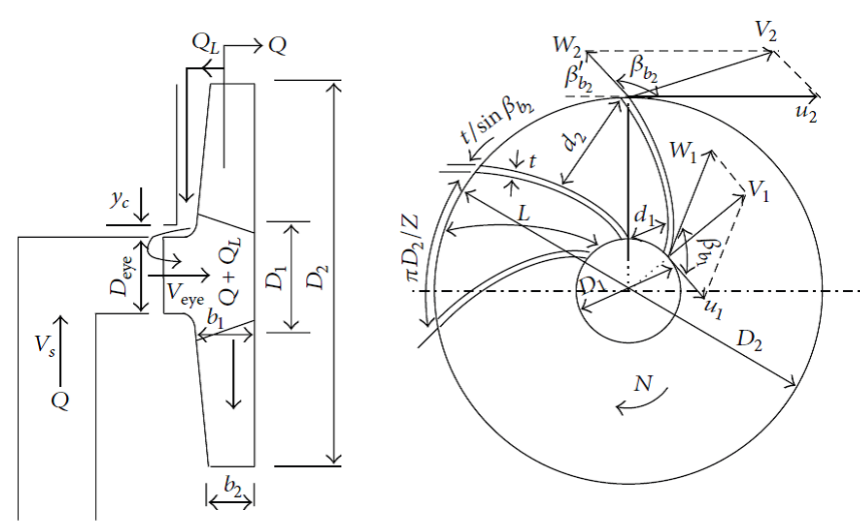

Fig. 1.3: Impeller's main geometrical characteristics (Taken from [48]) $\mathrm{D}_{1}=$ impeller inlet diameter, $\mathrm{D}_{2}=$ impeller exit diameter, $\beta_{\mathrm{b} 1}=$ blade angle at impeller leading edge, $\beta_{\mathrm{b} 2}=$ blade angle at impeller trailing edge, $\theta_{\mathrm{w}}=$ wrap angle.

\subsection{Previous Design efforts}

Centrifugal pumps are designed in order to be fitted to installations and work over a wide range of operating conditions. In such cases the prediction of performance is of primary importance for safe and effective operation of pumps and constitutes an important challenge for the pump designer. The challenge becomes particularly difficult when it is necessary to predict the performance of different types of centrifugal pumps varying from low to high volume flow rates.

Improving pump efficiency needs a good understanding of its components behavior at design point and off-design conditions. As measurement technologies for more accurate flow field studies are limited and they are expensive, due to complicated nature of geometry and the flow itself, numerical models have been developed and extended for performance prediction and primary design steps. However, numerical results would be more reliable if more experimental data were available for validation.

Last years the trend in pump industry [1-6] is to emphasize to the blade shape configuration. The reason behind this trend is the need for an effective way to achieve fast predictions methods for pump maps construction avoiding multiple steps in the test rig, [7-11].

The principal objective of centrifugal pump design effort, according to [12-18] is the effective matching between pump operation and impeller geometry. It is important to choose such a centrifugal pump morphology that the pump's operating line falls within the pump's high-efficiency region [19-27] . Therefore, a variety of approximate methods or numerical precedures have been developed aiming to predict centrifugal pump performance characteristics [28,33]

Predictions of centrifugal pump performance maps were also obtained by using advanced 3D Computational Fluid Dynamics (CFD) techniques, most commonly solving the Reynolds Averaged Navier Stokes (RANS) equations, coupled with a turbulence model. However there are a number of disadvantages when using CFD methods except their high computational cost and the lack of experimental data for validation.

Sometimes for example, prediction of centrifugal pump performance constitutes an important challenge when a pump has to be manufactured in order to be fitted in a given installation and to work over a wide range of operating conditions, [30], [31], [32]. The challenge becomes particularly difficult when is needed to predict the performance of different types of centrifugal pumps varying from low to high volume flow rates Pfeiderer [7]. In all these cases characteristic curves are not always available to evaluate the adequacy of the pump's performance for a particular situation and CFD methods canot help adequately. As a result there is a need for fast practical but accurate methods as the one presented in this work.

\subsection{The current approach}

The present study presents a fast method to estimate pump performance characteristics requiring only a few pump geometrical data. Centrifugal pump performance curves were produced using polynomial functions while the experimental data points were known by the pump's test rig measurements. By using efficiency curves from six different known pumps,we tried to find a closed form for the coefficients of the head performance that approximates the performance maps. Alternative curve fitting methods using exponential as well as polynomial functions for the blade angle $\beta=f(\rho)$ or the volute radius $\rho=g(\beta)$ were proposed too.

The first step of method presented here, (named The Trojan horse method) is to propose algorithms for the internal geometry of the impeller blades. As a second step calculates the distribution of the degree of efficiency as a function of both the $n_{q}$ and the morphology of the blade curvature. From the proposed efficiency polynomial results by integration-with appropriate approaches-the polynomial of manometer characteristic distribution. That is, that starting from internal blading we finally end up by obtaining the final pump characteristics. Due to the fact that starting with a few internal pump features we finally get to know the characteristics of the 
pump as a whole we have called our method: The Trojan horse method.

The overall efficiency is estimated, not only the head. The numerical predictions are compared to experimental data for centrifugal pumps delivering low, medium and high volume flows. The data was either obtained in the test rig or found in the literature.

The results show that the proposed method can be used as a tool to the pump designer in order to obtain a quick assessment of performance curves.

Taking into account the challenging complexity of centrifugal pump performance map prediction, the present article aims to simplify and generalize to the extent that it is possible a method focused on sizing centrifugal pumps, predicting their performance map from very low to very high volume flow rate, requiring only a minimum number of geometrical data that is readily available.

Most of the authors cited in the literature survey above have analyzed several pumps geometries in their studies. In the present article these pumps are examined as applications to evaluate the increased applicability of the method, called Trojan horse method.

\section{CAlCUlations' METHODOLOGY}

\subsection{General Assumptions}

According to the present design procedure, we assume that there is a casing that encloses the outer circumference of the radial impeller.The design approach assumes that a vortex phenomenon is mainly responsible for the fluid transport[3438]. The present method employs a group of empirical euations in terms of a polynomial algorithm in order to estimate the pump performances. The input data required are the following:
(i) Impeller inlet diameter, $\mathbf{D}_{\mathbf{1}}$,
(ii) Impeller exit diameter, $\mathbf{D}_{\mathbf{2}}$
(iii) Number of impeller blades, $\mathbf{z}$
(iv) Blade angle at impeller trailing edge, $\boldsymbol{\beta}_{2}$

The basic assumptions of the present method are the following:
(i) Empirical equations for $\eta_{\max }$ are developed for different impeller's rotational speeds,
(ii) The prediction method takes into account the flow in the pump impeller as well as the effect of volute.

\subsection{Methodology}

The main steps of the pump performance map prediction procedure are the following :

Step 1: Estimation of the operable volume flow rate employing novel empirical relations and using impeller geometrical data.

Step 2: Approximation of the performance curves for various impeller speeds by means of novel empirical functions.

The originality of the present method lies on:

(a) the calculation of the shut-off maximum head attained by the pump,

(b) the derivation of a set of equations that estimate the volume flow rates at each constant speed characteristic line of the centrifugal pump and (c) the suggestion of novel empirical relations for the shape of the characteristic curves of the performance map such as $\eta_{\mathrm{a}}(\varphi$,wrap angle $)$ and $\eta_{\mathrm{b}}\left(\mathrm{n}_{\mathrm{q}}\right)$.

\subsubsection{Distribution Strategy}

All the above described equations contain an algorithm for the pump impeller geometrical data, its blade number and its rotational speed.

When designing centrifugal impeller, the pump impeller and the geometric parameters of the design point must achieve the pump design conditions and maximum efficiency, $\boldsymbol{\eta}_{\text {max }}$. However $\eta_{\max }$ varies with $\theta_{\mathrm{w}}$. We used Eq.3.6 to examine the effect of wrap angle on $\boldsymbol{\eta}_{\text {max. }}$. The results are shown in Table 2.1 and Fig.2.1. We see that. $\eta_{\max }$ increases until $\theta_{\mathrm{w}}=100^{\circ}$, then decreases. Thus, each centrifugal pump with exact parameters at the design point has perfect $\boldsymbol{\eta}_{\max }$ at a specific wrap angle.

Table 2.1 Calculations of efficiency as a function of wrap angle

\begin{tabular}{|c|c|}
\hline$\theta_{\mathrm{w}}$ & $\eta_{\max }=1.6\left[-2\left(10^{-6}\right) \theta_{\mathrm{w}}{ }^{3}+0.00045 \theta_{\mathrm{w}}{ }^{2}-0.03 \theta_{\mathrm{w}}+1.1\right][28]$ \\
\hline 50 & 0.76 \\
\hline 55 & 0.7656 \\
\hline 60 & 0.7808 \\
\hline 65 & 0.8032 \\
\hline 70 & 0.8304 \\
\hline 75 & 0.86 \\
\hline 80 & 0.8896 \\
\hline 85 & 0.9168 \\
\hline 90 & 0.9392 \\
\hline 95 & 0.9544 \\
\hline 100 & 0.96 \\
\hline 105 & 0.9536 \\
\hline 110 & 0.9328 \\
\hline 115 & 0.8952 \\
\hline 120 & 0.8384 \\
\hline 125 & 0.76 \\
\hline
\end{tabular}

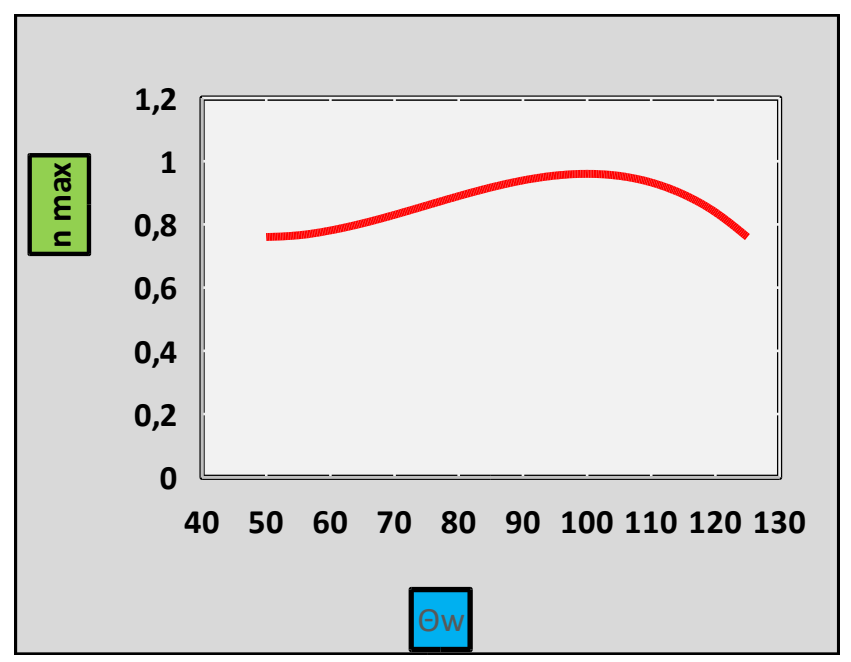

Fig.2.1.Efficiency as function of wrap angle 
Convenient forms of the blade angle are shown below in Tables 2.2 and 2.3 where: $\beta\left(\mathrm{r}_{1}\right)=\beta_{1}, \beta\left(\mathrm{r}_{2}\right)=\beta_{2}$ or $\mathrm{r}\left(\beta_{1}\right)=$ $\mathrm{r}_{1}, \mathrm{r}\left(\beta_{2}\right)=\mathrm{r}_{2}$. The constants $\boldsymbol{\alpha}$ and $\mathbf{c}$ in Tables 2.2 and 2.3 are calculated by curve fitting experimental results.

I) In the case that we know $r$ and try to find $\beta$ then any distribution pattern for $r$ from Table 2.2 can be chosen. In the case however that we only choose the algorithmic status for a parameter $\beta$ or $r$, then the combinations may be variegally complex or they can only come from the linear patterns. This means that when a model function is selected, the other one must be linear.

\begin{tabular}{|c|c|}
\hline$\beta=\beta(r)$ & Conditions : $\beta_{1}=\beta\left(r_{1}\right), \beta_{2}=\beta\left(r_{2}\right)$ \\
\hline$\beta=\alpha \mathrm{r}+\mathrm{c} / \mathrm{r}$ & $\beta_{1}=\alpha r_{1}+c / r_{1} \quad \beta_{2}=\alpha r_{2}+c / r_{2}$ \\
\hline$\beta=\alpha \mathrm{r} \mathrm{e}^{\mathrm{cr}}$ & $\beta_{1}=\alpha r_{1} e^{c r_{1}} \quad \beta_{2}=\alpha r_{2} e^{c r_{2}}$ \\
\hline$\beta=\alpha \mathrm{e}^{\mathrm{cr}}$ & $\beta_{1}=\alpha e^{c r_{1}} \quad \beta_{2}=\alpha e^{c r_{2}}$ \\
\hline$\beta=\alpha r^{2}+c$ & $\beta_{1}=\alpha r_{1}^{2}+c, \beta_{2}=\alpha r_{2}^{2}+c$ \\
\hline
\end{tabular}

II) In the case that we know $\beta$ and try to find $r$ then any distribution pattern for $\beta$ from Table 2.2 can be chosen..

In addition to Sigloch [40], Menny [41] or Bowade [42] fluid dynamic models, practical applications allows the presentation of functions that can analogously approximate the curvature that clearly results from the impeller geometry.

\begin{tabular}{|c|c|}
\hline $\mathrm{r}=\mathrm{r}(\beta)$ & \multicolumn{2}{|c|}{ Conditions: $\mathrm{r}_{1}=\mathrm{r}\left(\beta_{1}\right), \mathrm{r}_{2}=\mathrm{r}\left(\beta_{2}\right)$} \\
\hline$r=r_{2} e^{(a \beta+c)}$ & $r_{1}=r_{2} e^{\left(a \beta_{1}+c\right)}, r_{2}=r_{2} e^{\left(a \beta_{2}+c\right)}$ \\
\hline$r=\alpha r_{1}+c$ & $r_{1}=\alpha r_{1}+c \beta_{1}, r_{2}=\alpha r_{2}+c \beta_{2}$ \\
\hline$r=(\alpha / \beta) e^{c}$ & $r_{1}=\left(\alpha / \beta_{1}\right) e^{c}, r_{2}=\left(\alpha / \beta_{2}\right) e^{c}$ \\
\hline$r=e^{\left(a \beta^{2}+c\right)}$ & $r_{1}=e^{\left(a \beta_{1}^{2}+c\right)}, \quad r_{2}=e^{\left(a \beta_{2}^{2}+c\right)}$ \\
\hline
\end{tabular}

III) Criteria for optimum pump design

For a certain number of revolutions, both the angle selection as well as the manometer head and the flow rate should give a tracking match to the blade curvature (Fig.2.2) for the different methods (Sigloch [40], Menny [41], Bowade [42] ) for $\varphi=\varphi_{\max }=\theta_{\mathrm{w}}$ [39].

$$
\theta_{w}=\frac{360}{z}\left[0.5793 \exp \left(\frac{-n_{q}-3.793}{89.87}\right)^{2}+2.158 \exp \left(\frac{-n_{q}+434.9}{1087}\right)^{2}\right]
$$

The basic function of a blade (Fig.2.2, Table.2.4) is to guide the flow. This means, that to impose a certain direction to the flow, the blade angle at a certain radius $\beta(\mathrm{r})$ should be imposed to the flow, guiding the flow to follow the same direction (Fig.2.2, Table.2.4).

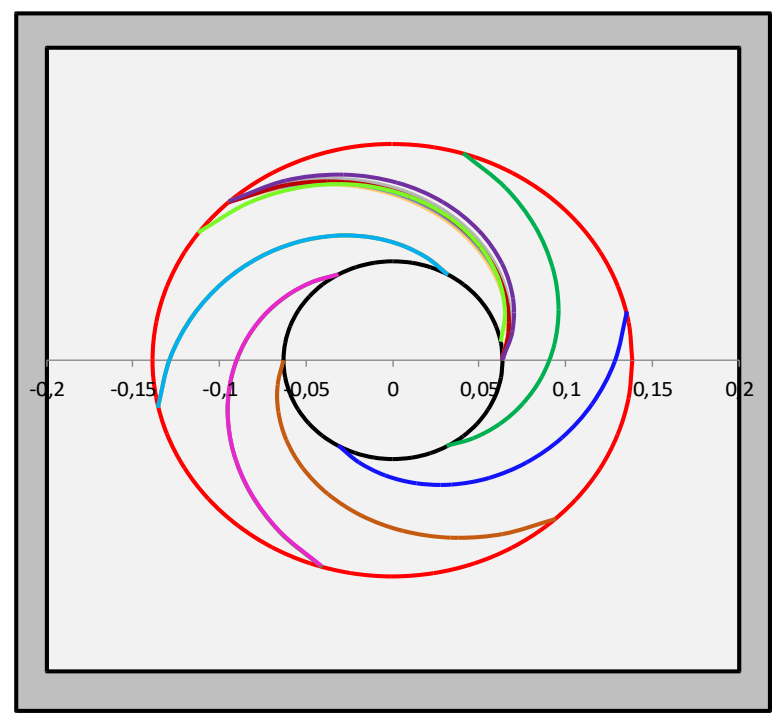

Fig.2.2 : Representation of a present study model

The details of the calculations and a summary of the various impeller geometrical constants are tabulated in Table 2.4 .

Table 2.4 Blade drawing positions

\begin{tabular}{|c|c|c|c|}
\hline $\mathrm{r}=\alpha^{*} \mathrm{e}^{(\mathrm{c} / \beta)}$ & $\mathrm{X}_{\mathrm{r}}=\mathrm{r} \cos \left(\pi \theta_{\mathrm{w}} / 180\right)$ & $\mathrm{Y}_{\mathrm{r}}=\mathrm{r} \sin \left(\pi \theta_{\mathrm{w}} / 180\right)$ & $\begin{array}{c}\varphi_{\mathrm{w}}(\text { linear }) \\
\quad 0 \rightarrow \theta_{\mathrm{W}}\end{array}$ \\
\hline 0.0391612 & 0.03916121 & 0 & 0 \\
\hline 0.0431289 & 0.04140874 & 0.012058868 & 14.68679 \\
\hline 0.0473821 & 0.04015604 & 0.025150709 & 29.37359 \\
\hline 0.0519305 & 0.03509634 & 0.038275598 & 44.06038 \\
\hline 0.0567829 & 0.02621048 & 0.050371751 & 58.74718 \\
\hline 0.061948 & 0.01376966 & 0.060398232 & 73.43397 \\
\hline 0.0674334 & -0.0016848 & 0.067412309 & 88.12077 \\
\hline 0.0732463 & -0.019381 & 0.070635657 & 102.8076 \\
\hline 0.0793932 & -0.0383706 & 0.069505244 & 117.4944 \\
\hline 0.0858798 & -0.0575919 & 0.063706558 & 132.1812 \\
\hline
\end{tabular}

2.2 .2

Volume flow estimation

The pump total head depends on the tangential velocity at impeller outlet (see Fig.2.3) expressed as:

$u_{2}=\pi \cdot D_{2} \cdot n$ 

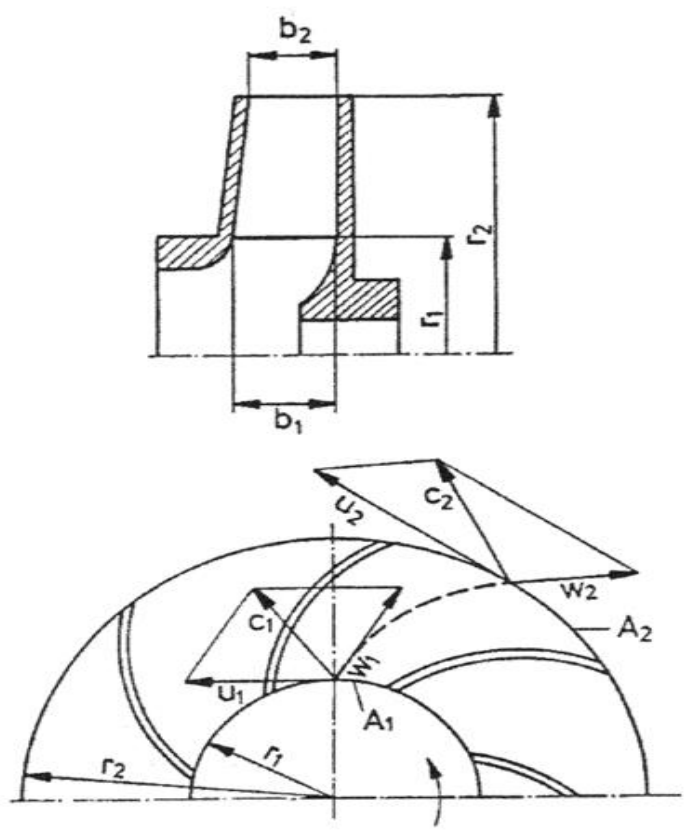

Fig.2.3: Velocity triangle at impeller

There is a variety of available correlations for the slip factor introduced in and verified against experimental data. The correlation adopted here, is the one suggested:

\subsubsection{Head estimation}

The present method proposes an original formula to calculate the head attainable, where a correction coefficient depending on the exit diameter $\mathrm{D}_{2}$ is adopted.

Equation approximates the maximum efficiency of centrifugal pump as a function of the blade tip configuration , based on the flow analysis performed.

The maximum head obtained by a centrifugal pump corresponds to throttling conditions, where the volume flow is zero.

\subsubsection{Efficiency performance curves estimation}

It is intended to approximate the shape of characteristic lines by means of a function which starts from a head high value when the ratio is close to zero (corresponding to shut off) and decays asymptotically as the ratio approaches the value 1 (corresponding to maximum value of the efficiency). The challenge of equations is to approximate the different shapes of centrifugal pump characteristic lines varying from low to high rotational speeds.

\subsubsection{Volute design}

The volute contour of the investigated pumps [9] when operating at a design volume flow rate, was found by applying some models that appear in Table. 2.5. In this Table, $\rho$ refers to the volute wall curvature and $\boldsymbol{\theta}_{\mathbf{0}}$ is the diffusor's angle. A program of experiments to see the formation of the flow, particularly through the region of the fixed pump blades was carried out in.
Table 2.5: The volute shape models

\begin{tabular}{|c|c|}
\hline $\mathrm{R}=\mathrm{R}(\theta)$ the volute shape & The shape design \\
\hline $\begin{array}{l}\text { The Archimedes' Shaped Spiral } \\
\text { Model } \\
\text { for } 0<\theta<2 \pi \\
\quad \mathrm{R}=\mathrm{ar}_{2}+\mathrm{c} \theta\end{array}$ & $\begin{array}{l}\quad \text { for } 2 \pi<\theta<4 \pi \\
X=R \cos (1.57 \theta / 90) \\
y=R \sin (1.57 \theta / 90)\end{array}$ \\
\hline $\begin{array}{l}\text { The Logarithmic-Shaped } \\
\text { Spiral Model } \\
\text { for } 0<\theta<2 \pi \\
\mathrm{R}=1.1 \mathrm{r}_{2} \mathrm{e}^{\mathrm{a} \theta+\mathrm{c}}\end{array}$ & $\begin{array}{l}\quad \text { for } 2 \pi<\theta<4 \pi \\
X=R * \cos (1.57 * \theta / 90) \\
y=R * \sin (1.57 * \theta / 90)\end{array}$ \\
\hline $\begin{array}{l}\text { Diffusor shape } \\
\quad \text { for } 2 \pi<\theta<4 \pi, 1<\xi<1.95 \\
\rho_{1}=\mathrm{r}_{2} \mathrm{e}^{[(\ln 2) \theta / 360-\ln 2]} \\
\rho_{2}=\mathrm{r}_{2}\left(1.01+0.08 \mathrm{n}_{\mathrm{q}} / 100+0.07 \mathrm{H}_{\mathrm{BEP}} /\right. \\
1000) \xi\end{array}$ & $\begin{array}{l}\text { Coordinates positions } \\
\text { of the blade tip } \\
\qquad \begin{array}{cc}\mathrm{x}_{\theta} & \mathrm{y}_{\theta} \\
\rho_{1} & 0 \\
\rho_{\theta} & \rho_{2}\end{array}\end{array}$ \\
\hline $\begin{array}{ll} & \text { Diffusor wall } \\
\theta_{\mathrm{o}} & \text { diffusor angle } \ldots \ldots .0<\theta_{\mathrm{o}}<5 \\
& \rho_{\theta}=\rho_{1}+\rho_{2} \tan \left(1.57 \theta_{\mathrm{o}} / 90\right)\end{array}$ & \\
\hline
\end{tabular}

The form and the constructional details of the volute geometry model are illustrated in Fig.2.4.

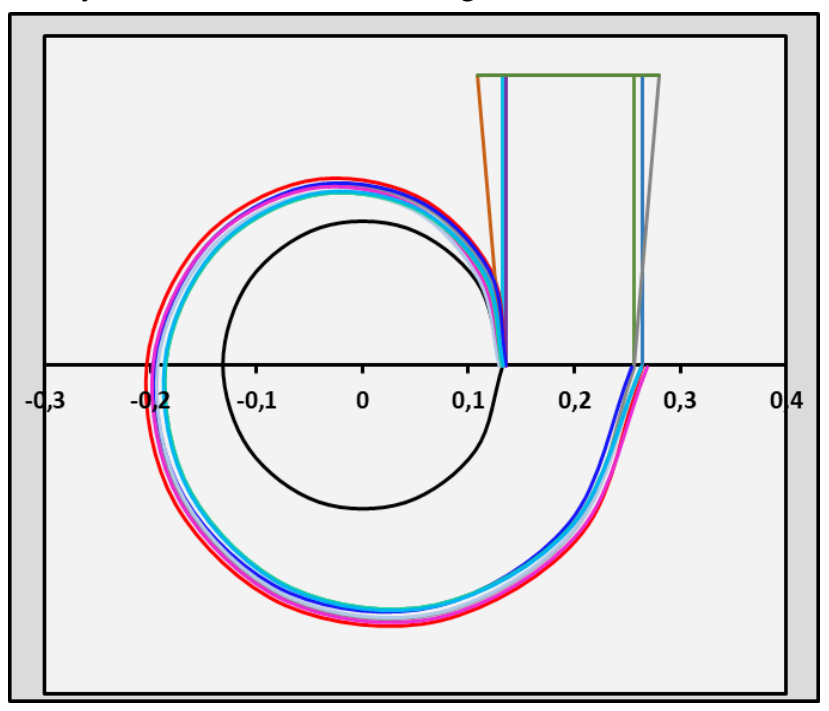

Fig.2.4: Typical arrangement of the casing with diffusor

\section{RESULTS}

In order to evaluate the accuracy of the model described above, various commercial pumps were considered as test cases, since their performance maps are available by their manufacturers. These maps were digitized using an appropriate software in order to be compared with the present method's results. For these pumps there were found numerical predictions in the literature, according to the authors' knowledge. Table 3.1 summarizes the most important data of the pumps chosen for the performance map prediction.

Table 3.1: pumps characteristics at BEP

\begin{tabular}{|c|c|c|c|c|c|c|c|}
\hline $\begin{array}{c}\text { Pump } \\
\text { name }\end{array}$ & $\begin{array}{c}\mathrm{b}_{2} \\
(\mathrm{~mm})\end{array}$ & $\begin{array}{c}\mathrm{D}_{2} \\
(\mathrm{~mm})\end{array}$ & $\beta_{2}$ & $\mathrm{z}$ & $\begin{array}{c}\mathrm{Q}_{\mathrm{BEP}} \\
\left(\mathrm{m}^{3} / \mathrm{h}\right)\end{array}$ & $\begin{array}{c}\mathrm{H}_{\mathrm{BEP}} \\
(\mathrm{m})\end{array}$ & $\begin{array}{c}\mathrm{n} \\
(\mathrm{RPM})\end{array}$ \\
\hline$[1]$ & 10 & 200 & $49^{0}$ & 9 & 62.5 & 62 & 3000 \\
\hline$[4]$ & 9 & 200 & $24^{0}$ & 5 & 45.68 & 46,41 & 2900 \\
\hline$[\mathbf{2}]$ & 11 & 160 & $23^{0}$ & 7 & 25 & 7 & 1450 \\
\hline$[5]$ & 15 & 130 & $20^{0}$ & 6 & 3.6 & 6 & 1500 \\
\hline$[3]$ & 30 & 300 & $22^{0}$ & 6 & 200 & 20 & 1450 \\
\hline$[6]$ & 26 & 240 & $25^{0}$ & 6 & 98 & 68 & 2900 \\
\hline
\end{tabular}


The calculational procedure for predicting the pump characteristic Curves, has as follows:

$$
\begin{aligned}
& \mathrm{Q}_{\mathrm{o}}=\mathrm{Q}_{\mathrm{BEP}} / \mathrm{\eta}_{\mathrm{q}} \\
& \mathrm{Q}_{\max }=1.6 \mathrm{Q}_{\mathrm{o}} \\
& \mathbf{J}=\mathbf{Q}_{\mathrm{i}} / \mathbf{Q}_{\mathbf{B E P}}
\end{aligned}
$$

The coefficient $\mathbf{j}$ modulates the empirical equations to the real performance curves of the pump geometry (Fig.2.3 ). The coefficient $\mathbf{j}$, represents the time interval of pumping time required for the volume flow to reach volume flow at BEP

$$
\begin{aligned}
& \eta_{1}=\left[-32+145 \log \left(n_{\mathrm{q}}\right)-41\left(\log \left(\mathrm{n}_{\mathrm{q}}\right)\right)^{2}\right] 0.01 \\
& \eta_{2}=\left[-2\left(10^{-6}\right) \theta_{\mathrm{w}}{ }^{3}+0.00045 \theta_{\mathrm{w}}{ }^{2}-0.03 \theta_{\mathrm{w}}+1.1\right] 1.6 \\
& \eta_{\max }=\left(\eta_{1}{ }^{1,9} \eta_{2}{ }^{0,1}\right)^{0,5} \\
& \left.\eta=0.86 \eta_{\max }\left[(\mathrm{z} / 7)^{0,1}\right)\left(1.33 j^{0,7}-0.3 j^{3}\right)\right] \\
& \mathbf{H}=\boldsymbol{\xi} \mathbf{H}_{\mathrm{u}}\left[\mathbf{1 - 0 . 1} \mathbf{j}^{\mathbf{1}, \mathbf{7}} \mathbf{- 0 . 0 3 5} \mathbf{j}^{\mathbf{4}}\right] \\
& \mathrm{H}_{\mathrm{u}}=\mathrm{H}_{\mathrm{BEP}} / \eta_{\mathrm{h}}, \mathrm{H}_{\mathrm{th}}=\left(\mathrm{u}_{2}{ }^{2}-\mathrm{u}_{1}{ }^{2}\right) / 9.81, \mathrm{H}_{\text {shut off }}=\mathrm{H}_{\mathrm{BEP}} / \eta_{\mathrm{m}} \\
& \text { where } \\
& \eta_{\mathrm{q}}=1 /\left[1+0.28 / \mathrm{n}_{\mathrm{q}}{ }^{0,66}\right] \text { is the volumetric efficiency } \\
& \eta_{\mathrm{m}}=1 /\left[1+1 / \mathrm{n}_{\mathrm{q}}\right] \text { is the mechanical efficiency } \\
& \eta_{\mathrm{h}}=1-0.071 / \mathrm{Q}_{\mathrm{BEP}}{ }^{0,25} \text { is the hydraulic efficiency } \\
& \xi \text { is the blade number effect factor [34-38,43-46] as } \\
& \xi=-0.013 z^{2}+0.1725 z+0.51 \\
& \eta \text { is the overall efficiency and } \\
& \mathrm{n}_{\mathrm{q}} \text { is the specific speed }
\end{aligned}
$$

We used Eq.3.8 and Eq.3.9 to obtain head and efficiency for different numbers of blades ( $\mathrm{z}=5-9$ ). The simulation (Fig.3.1) showed strong effect of the number of blades on $\xi$. The blade effect factor $\xi$ (Fig.3.1) increases obviously with a specific number of blades, then decreases. Thus, each centrifugal pump with exact parameters at the design point has perfect head and efficiency performances at a specific blade number.

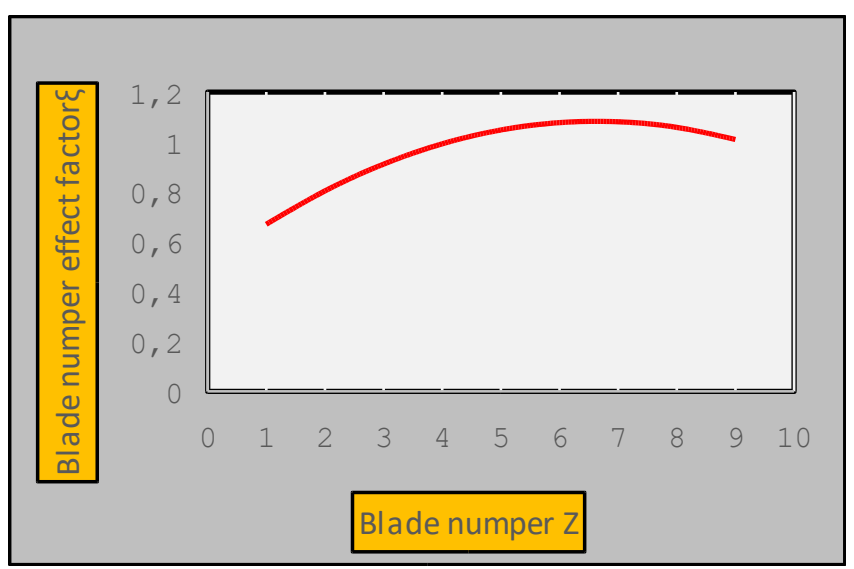

Fig.3.1. The relation between blade number effect factor $\xi$ and the number of blades $\mathrm{z}$.

Figs.3.2-3.7 present the calculational results of the above equations (3.2-3.14) compared to the real pump data of Table 3.1. In these figures the two procedures (experimental vs predicted) are shown as poly. As we can see, (Figs.3.2-3.7) the approach with the new prediction method is very good, since the curves created are close to the actual operating points of the pumps given by the six authors [1-6].

\subsection{Grapsas-Anagnostopoulos-Papantonis [1]}

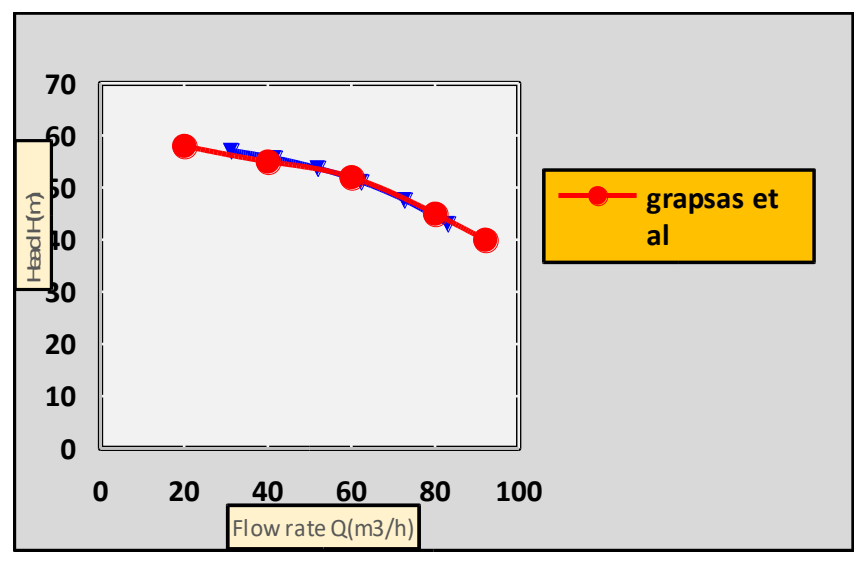

Figure 3.2 Using present model to predict pump [1] Head characteristics

\subsection{Zhang Yongxue, Zhou Xin, Ji Zhongli and Jiang Cuiwei [4]}

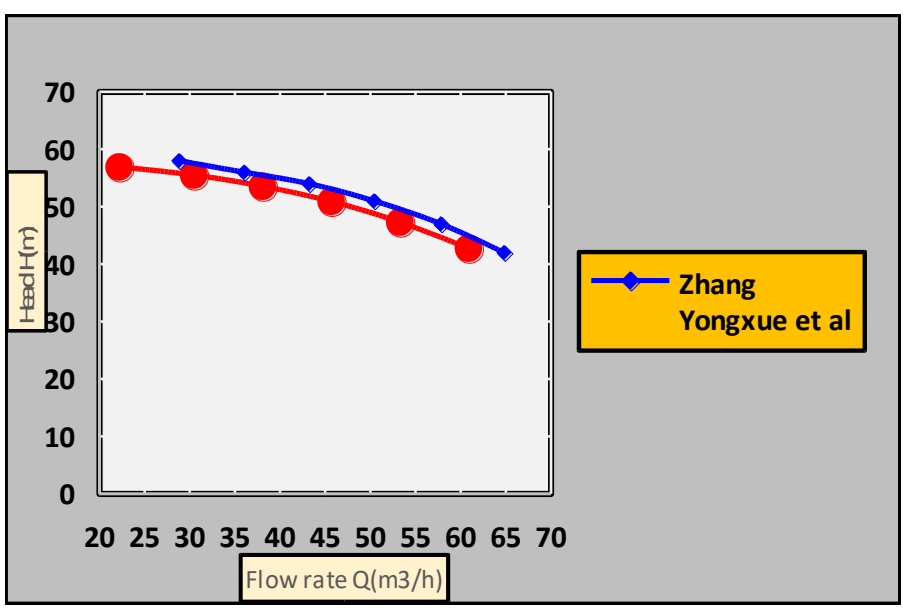

Figure 3.3 Using present model to predict pump [4] Head characteristics

\subsection{Lei Tan, Shuliang Cao, Yuming Wang and Baoshan Zhu [2]}

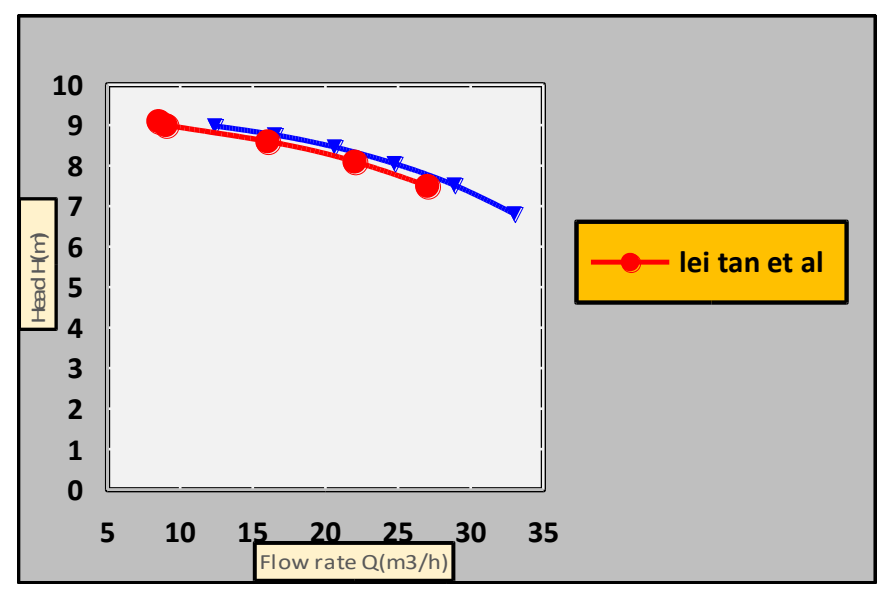

Figure 3.4a Using present model to predict pump [2] $\mathrm{H}$ ead characteristics 


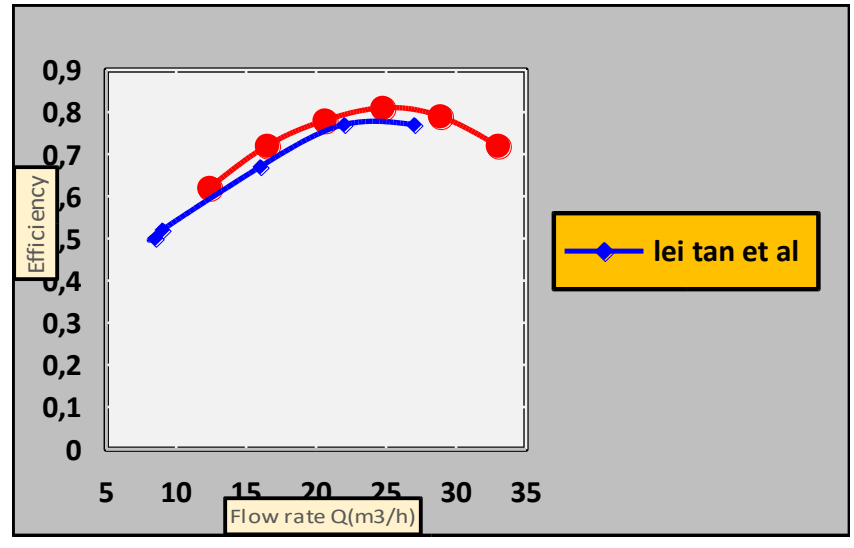

Figure 3.4b Using present model to predict pump [2] efficiency

3.4 A. Farid Ayad Hassan, H. M. Abdalla, A. Abou ElAzm Aly [5]

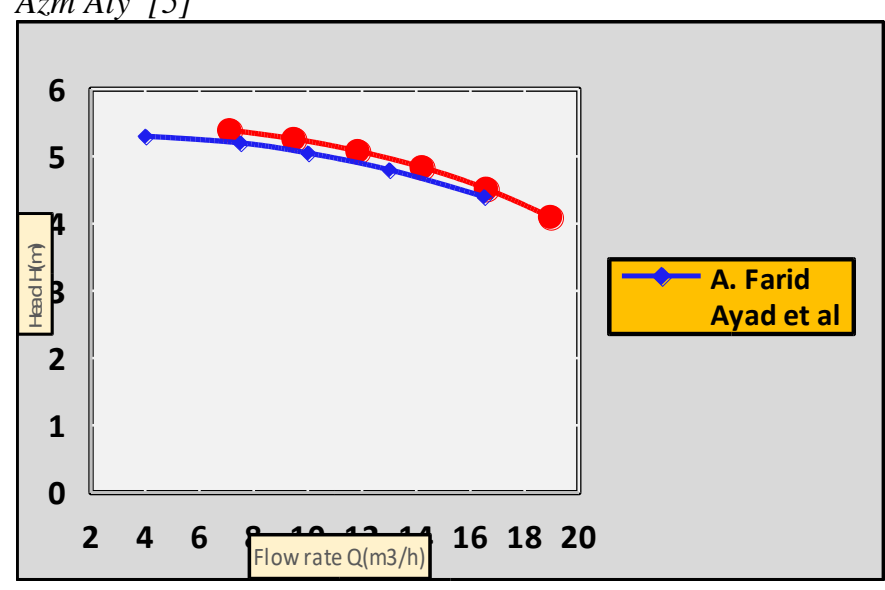

Figure 3.5a Using present model to predict pump [5] Head characteristics

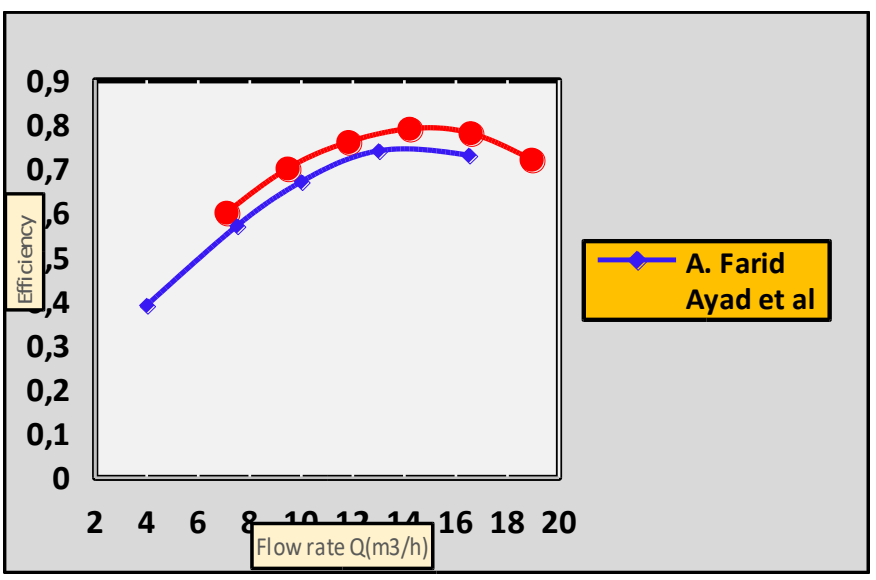

Figure 3.5b Using present model to predict pump [5] efficiency
3.5 Xin Zhou, Yongxue Zhang, Zhongli Ji, and Long Chen

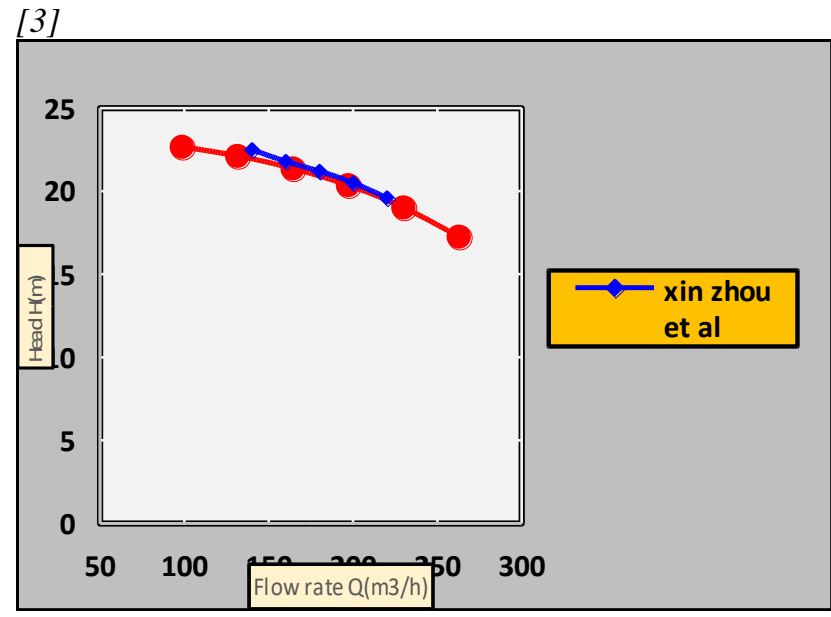

Figure 3.6a Using present model to predict pump [3] Head characteristics

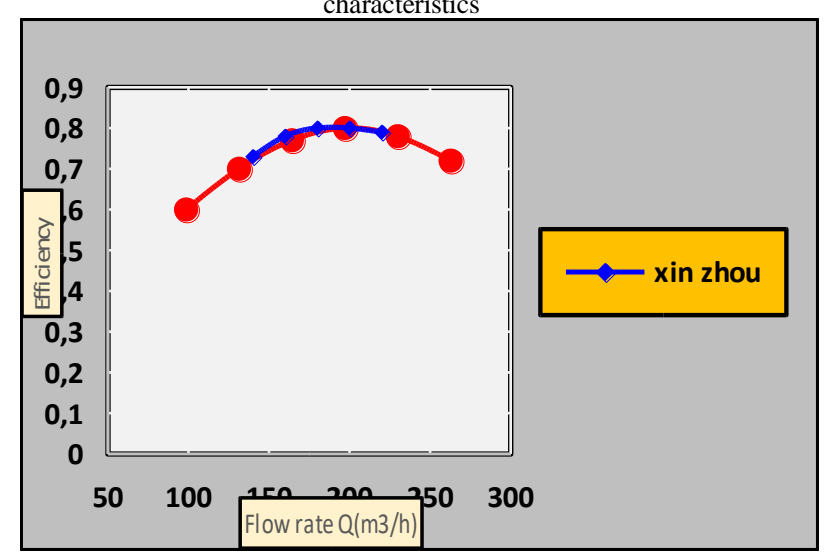

Figure 3.6b Using present model to predict pump [3] efficiency

3.6 Tahani \& Pourheidari [6]

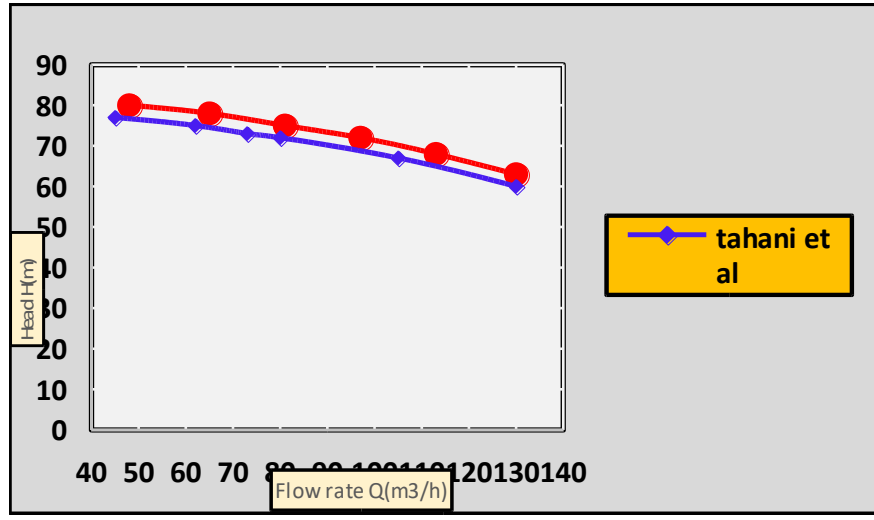

Figure 3.7a Using present model to predict pump [6] Head characteristics. 


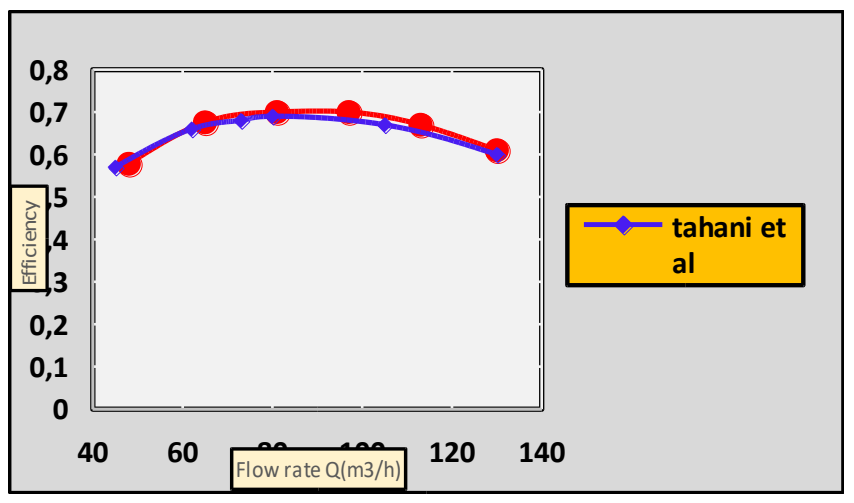

Figure 3.7b Using present model to predict [6] pump efficiency

\section{CONCLUSIONS}

In this study, an original methodology for the challenging topic of centrifugal pump performance prediction for industrial applications was presented. The motivation for this work was to introduce a fast engineering assessment tool which is able to predict both the operating limits of centrifugal pumps in terms of volume flow rates as well as the shape of its performance curves. The model is based on a pioneering methodology using empirical relations of the mean flow upstream and downstream of the centrifugal impeller. The minimum and the maximum volume flows are approximated by means of genuine fist issued empirical equations. The Head and the efficiency that any pump can reach is estimated by means of the impeller outlet diameter and the local $\eta_{\max }$.

Two original functions are introduced in order to generate the shape of the performance curves of the pump, namely polynomial functions. Evaluation of the method is done by considering commercial pumps with known performance maps from their researchers, of various speeds. The results obtained can be summarized in the following Table 4.1:

Table 4.1: Evaluation of results

\section{- Good agreement at intermediate RPM}

- Better agreement with measurements when the polynomial functions are used

The simple and fast method presented here was validated succesfully against some models of centrifugal pumps for which experimental data were found in the literature or from the test rig. Comparisons between numerical and experimental data obtained in the test rig show that the proposed model can satisfactorily predict performance characteristics of centrifugal pumps, for the cases examined.

As it could be observed, the approximation between performance curves estimated via experiments test or via empirical mathematical formulas is quite good. In this way the performance of a typical centrifugal pump could be mathematically provided without the need of the expensive experimental procedure.

The development of the present study calculational procedure is due to the fact that centrifugal pumps have an important contribution in industrial world. Accordingly to the international standards of centrifugal pumps, the present study presents an analysis system for obtaining the performance curves of six pumps. The pump characteristics performances have been tested on different types of centrifugal pumps and the obtained results prove the accuracy and high capability of the implemented method.

Conclusively, the proposed method could be beneficial to the pump industry in the early design stages. Future work will cope with the extension of the method to predict the head and the efficiency of more than 100 centrifugal pumps.

\begin{tabular}{|c|c|}
\hline \multicolumn{2}{|c|}{ Nomenclature } \\
\hline D & Impeller diameter \\
\hline n & Rotational speed \\
\hline H & Pump Head \\
\hline z & Blade number \\
\hline Q & Volumetric flow rate \\
\hline $\mathrm{b}$ & Blade width \\
\hline $\mathrm{R}$ & Radius \\
\hline \multicolumn{2}{|c|}{ Greeks } \\
\hline$\beta$ & Blade angle \\
\hline$\eta$ & Efficiency \\
\hline$\theta$ & Inclination angle \\
\hline$\rho$ & Fluid density \\
\hline$\omega$ & Impeller angular velocity \\
\hline \multicolumn{2}{|c|}{ Subscripts } \\
\hline 1 & Impeller inlet \\
\hline 2 & Impeller outlet \\
\hline
\end{tabular}

\section{REFERENCES}

[1] Vasilios A. Grapsas, John S. Anagnostopoulos and Dimitrios-E. Papantonis, PARAMETRIC STUDY AND DESIGN OPTIMIZATION OF A RADIAL-FLOW PUMP IMPELLER , 2nd International Conference "From Scientific Computing to Computational Engineering" 2nd IC-SCCE Athens, 5-8 July,2006@IC-SCCE

[2] Lei Tan, Shuliang Cao, Yuming Wang and Baoshan Zhu-Direct and inverse iterative design-method for centrifugal pump impellers, Proc IMechE Part A: J Power and Energy 1-12, IMechE 2012

[3] Xin Zhou, Yongxue Zhang, Zhongli Ji, and Long Chen, The Impeller Improvement of the Centrifugal Pump Based on BVF Diagnostic Method , Hindawi Publishing Corporation Advances in Mechanical Engineering 2014.

[4] Zhang Yongxue, Zhou Xin, Ji Zhongli and Jiang Cuiwei, Numerical Design and Performance Prediction of Low Specific Speed Centrifugal Pump Impeller, International Journal of Fluid Machinery and Systems DOI: 10.5293/IJFMS.2011.4.1.133 Vol. 4, No. 1, January-March 2011

[5] A. Farid Ayad Hassan , H. M. Abdalla , A. Abou El-Azm Aly CENTRIFUGAL PUMP PERFORMANCE ENHANCEMENT BY BLADE SHAPE MODIFICATION, Proceedings of ASME Turbo Expo 2017 : Turbomachinery Technical Conference and Exposition GT2017 June 26-30, 2017, Charlotte, NC, USA

[6] M. Tahani, V, Pourheidari , Numerical Study of Incompressible Viscous and Turbulent Flow through the Centrifugal Pump ,Fluid Mechanics Letters 1 (2017) 27-35

[7] Pfeiderer, C., 1938, "Vorausbestimmung der Kennlinien schnellläufiger Kreiselpumpen.” VDI, Düsseldorf.

[8] Engeda, A., 1987, Untersuchungen an Kreiselpumpen mit offenen und geschlossenen Laufrädern im Pumpen- und Turbinenbetrieb. Ph.D. thesis TU Hannover.

[9] Athanassiadis, doctor thesis 1961 ETH-Zuerich ,Potential flow through spiral casings,

[10] Gülich, J.F., 1988, "Bemerkungen zur Kennlinienstabilität von Kreiselpumpe". Pumpentagung Karlruhe, B3.

[11] Japikse, D., Marscher, W.D., Furst, R.B., 1997. Centrifugal Pump Design and Performance, Concepts ETI Inc., Vermond.

[12] Karassik, I.J., Krutzsch, W.C., Fraser, W.H. and Messina J.P., 1976, Pump Handbook, McGraw-Hill Book Co, New York.

[13] Amminger, W.L., Bernbaum, H.M. 1974. "Centrifugal pump performance prediction using computer aid", Computers and Fluids, 2, pp.163-172. 
[14] Yedidiah S., 2003, "An overview of methods for calculating the head of a rotordynamic impeller and their practical significance", Proceedings of the Institution of Mechanical Engineers, Part A: Journal Process Mechanical Engineering, 217(3), pp.221-232.

[15] Auslaender J.,Hauptabmessungen von Kreiselpumpen, Zeitschrift Konstruktion, 10 Jahrgang, 1958, pp 407-410.

[16] Bohl W., Stroemungsmaschinen I and II, Vogel-Verlag, 1998.

[17] Vlachakis N. 1974. "Vergleich zweier Geschwindigkeitansätze für die radiale Spaltrichtung in Bezug auf das Drehmoment der rotierenden Scheibe". Bericht Uni Karlsruhe

[18] Berichte von Stroemungsmaschinen-stroemungslehre reihe Universitaet Karlsruhe

[19] Wesche, W.: Experimentelle Untersuchungen am Leitrad einer radialen Kreiselpumpe. Dissertation, TU Braunschweig (1989)

[20] Schubert,F.:Untersuchungen der Druck-u. Geschwindigkeitsverteilung in Radseitenräumen radialer Kreiselpumpen. Dissertation, TU Braunschweig (1988)

[21] Pfleiderer, C.: Die Kreiselpumpen für Flüssigkeiten und Gase, 5. Aufl Springer, Berlin - 1961

[22] Stepanoff, A.J.: Radial- und Axialpumpen, 2. Aufl. Springer, Berlin (1959)

[23] Sédille, M.: Turbo-Machines Hydrauliques et Thermiques. Masson \& Cie (1967)

[24] Busemann, A.: Das Förderverhalten radialer Kreiselpumpen mit logarithmisch-spiraligen Schaufeln. ZAMM 8(5), (1958)

[25] Kaewnai S, Chamaoot $M$ and Wongwises S 2009. Predicting performance of radial flow type impeller of centrifugal pump using CFD J. Mech. Sci. Techno. 23, pp 1620-1627.

[26] Anagnostopoulos J, 2006. CFD Analysis and Design Effects in a Radial Pump Impeller WSEAS Transactions on Fluid Mechanics,1,pp 763-770

[27] Mentzos M, Filios A, Margaris P and Papanikas D 2005. CFD predictions of flow through a centrifugal pump impeller. Proceedings of International Conf. Experiments/Process/System Modelling/ Simulation/Optimization. Athens, pp. 1-8

[28] Paeng, K.S., Chung, M.K., "A new slip factor for centrifugal impellers", Proceedings of the Institution of Mechanical Engineers, Part A: Journal of Power and Energy, Vol.215, 2001, pp.645-649.

[29] Bronshtein, I.N., Semendyayef, K.A., Musiol, G., Mühlig, H., Handbook of Mathematics, sixth edition, Springer-Verlag, 2015.

[30] Samani, Z., 1991, "Performance estimation of close-coupled centrifugal pumps". American Society of Agricultural Engineers, 7, pp.563-565.

[31] A \& M Emami,Design and Implementation of an Online Precise Monitoring and Performance Analysis System for Centrifugal Pumps IEEE Transactions on Industrial Electronics 2017

[32] ANDRZEJ WILK, The Analysis of the Influence of the Initial Impeller on the Discharge and the Delivery Head of High Speed Pump with Radial Blades Volume 4, October 2009

[33] A. J. Acosta R. D. Bowerman AN EXPERIMENTAL STUDY OF CENTRIFUGAL PUMP IMPELLERS Report No. E-19. 8 August 1955 - Office of Naval Research Department of the Navy
[34] Angela Gerlach The Influence of Impeller Designs on the Performance of a Vortex Pump, Berlin thesis 2018.

[35] Hayder Kareem Sakran, NUMERICAL ANALYSIS OF THE EFFECT OF THE NUMBERS OF BLADES ON THE CENTRIFUGAL PUMP PERFORMANCE AT CONSTANT PARAMETERS International Journal of Mechanical Engineering and Technology (IJMET) Volume 6, Issue 8, Aug 2015, pp. 105-117

[36] E. Korkmaz†, M. Gölcü and C. Kurbanoğlu Effects of Blade Discharge Angle, Journal of Applied Fluid Mechanics, Vol. 10, No. 2 pp. 529-540, 2017.

[37] Amin Habibi Sarbanani, A numerical study on the influence of the blade number and rotational speed on the centrifugal pump performance under two-phase flow Journal of Engineering (IOSRJEN) International organization of Scientific Research ,2016

[38] K.M. Pandey, A.P. Singh and Sujoy Chakraborty , NUMERICAL STUDIES ON EFFECTS OF BLADE NUMBER VARIATIONS ON PERFORMANCE OF CENTRIFUGAL PUMPS AT 2500 RPM, Journal of Environmental Research And Development Vol. 6 No. 3A, Jan-March 2012863

[39] Hydraulic design method for low specic speed overload free centrifugal pump impeller, google patent ,2014-11-26 CN 201410712052

[40] Ashish Bowade, Charu Parashar, A Review of Different Blade Design Methods for Radial Flow Centrifugal Pump , International Journal of Scientific Engineering and Research (IJSER) : 2347-3878, 2014

[41] Menny, K Stroemungsmaschinen, Teuner-Verlag 1985

[42] Sigloch ,H Stroemungsmaschinen, Hanser-Verlag 1984

[43] Adel Pourtaghia, Heidar Pouladib , Numerical Investigation of the Effect of the Number of the Blades of the Impeller on the Performance of Centrifugal Pumps Mapta Journal of Mechanical and Industrial Engineering (MJMIE), Vol. 2, No. 1, April, 2018

[44] LIU Houlin, WANG Yong, YUAN Shouqi, TAN Minggao, and WANG Kai, Effects of Blade Number on Characteristics of Centrifugal Pumps ,CHINESE JOURNAL OF MECHANICAL ENGINEERING Vol.23, 2010

[45] Sujoy Chakraborty, K.M. Pandey, Bidesh Roy, Numerical Analysis on Effects of Blade Number Variations on Performance of Centrifugal Pumps with Various Rotational Speeds International Journal of Current Engineering and Technology 2012 INPRESSCO.

[46] Hassan, Mohamed Izzedin DOCTORAL THESIS 1946 Der Einfluss der Schaufelzahl des Laufrades auf den Wirkungsgrad bei Kreiselradmaschinen eth ZUERICH

[47] http://www.globalpumps.in/beacon.htm

[48] Mohammed Ahmed El-Naggar, "A One-Dimensional Flow Analysis for the Prediction of Centrifugal Pump Performance Characteristics", International Journal of Rotating Machinery, Volume 2013, pp.1-19 